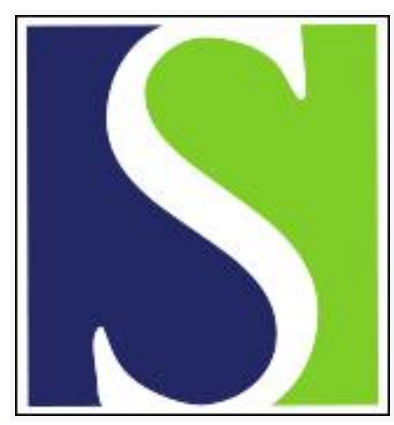

Scand J Work Environ Health 1990;16(5):329-333

https://doi.org/10.5271/sjweh.1776

Issue date: 00 Oct 1990

Congenital malformations among children of women working with video display terminals.

by Brandt LP, Nielsen CV

Affiliation: Institute of Social Medicine, University of Aarhus, Denmark.

This article in PubMed: www.ncbi.nlm.nih.gov/pubmed/2255873

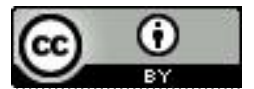




\title{
Congenital malformations among children of women working with video display terminals
}

\author{
by Lars PA Brandt, MD,1, 2 Claus V Nielsen, MD ${ }^{1,2}$
}

\begin{abstract}
BRANDT LPA, NIELSEN CV. Congenital malformations among children of women working with video display terminals. Scand $J$ Work Environ Health 1990;16:329-33. In a case-base study among 214108 commercial and clerical employees in Denmark the potential effect of the use of video display terminals on the risk of congenital malformations in pregnancy was investigated. The study base was identified by means of register linkage of the Medical Birth Register and the National Register of In-Patients. In the source population 24352 pregnancy outcomes were registered, 661 of which with congenital malformations entered the case group, and a base sample of 2252 pregnancies was drawn. Data concerning the use of video display terminals, job stress, ergonomic factors, exposure to organic solvents, and life-style factors were obtained from postal questionnaires. The results of this study did not support the hypothesis that the use of video display terminals during pregnancy is associated with an increased risk of congenital malformations.
\end{abstract}

Key terms: job stress, pregnancy outcome, reproductive failures, work during pregnancy.

Clusters of adverse pregnancy outcomes have been reported for women working with a video display terminal (VDT). Although such clusters are expected to occur by chance, they have led to increased concern about the potential reproductive hazards of VDT use. Low-frequency magnetic fields, job stress, and ergonomic factors have been suggested as potential risk factors (1).

Experimental studies on chicken embryos and pregnant mice exposed to low-frequency magnetic fields have shown contradictory results regarding reproductive hazards.

Four large-scale epidemiologic studies on VDT use and congenital malformations have been published. Kurppa et al (2) found an odds ratio (OR) of 0.9 for all malformations (controlled for confounders) and an OR of 1.6 for cardiac defects. Both results were statistically nonsignificant. Ericson \& Källén (3) found a statistically significant increased $O R$ for congenital malformation of 1.7 for VDT use in pregnancy, of 2.0 for VDT use for less than $10 \mathrm{~h} /$ week, and of 2.7 for VDT use for more than $10 \mathrm{~h} /$ week during early pregnancy. In their study, McDonald et al (4) found no increase in the observed to expected ratio for congenital malformation. Finally, a recently published study by Goldhaber et al (5) showed an increased OR of 1.4 (not significant) for women working with a VDT for more than $5 \mathrm{~h}$ /week.

1 Institute of Social Medicine, University of Aarhus, Aarhus, Denmark.

2 Department of Occupational Medicine, Municipal Hospital of Aarhus, Denmark.

Reprint requests: Dr LPA Brandt, Institute of Social Medicine, University of Aarhus, Hoegh Guldbergsgade 8, DK-8000 Aarhus, Denmark.
It has been argued that the increased frequency of reproductive failures among VDT workers, as seen in some previous studies, is due to methodological problems, such as selective memory of exposure (information bias), bias of selection, or confounding due to job stress or ergonomic factors. Still, Goldhaber et al stated that VDT work for more than $20 \mathrm{~h} /$ week should be considered a reproductive hazard.

A VDT is used frequently in many jobs today, and in the future such devices will be used in even more. Thus a slight increase in the risk of adverse pregnancy outcome by VDT use would have substantial public health consequences. Large-scale studies and weighted comparative analyses of several methodologically sound studies are needed.

The aim of the present case-base study was to investigate the potential effect of VDT use on the risk of congenital malformations among pregnant clerical and commercial employees in Denmark. Job stress, ergonomic factors, and other occupational and nonoccupational risk factors were taken into consideration, and finally the direction of selection and information bias was estimated.

\section{Subjects and methods}

\section{Selection of subjects and information}

The study was conducted as a case-base study (6). The source population was defined as all 15- to 44-yearold female members with at least one month's membership in the Union of Commercial and Clerical Employees in Denmark from 1982 to 1985. In all, 214108 women fulfilled these criteria, and all the women were registered by their personal identification number. The personal identification number is the main key of iden- 
tification in Denmark, as persons are identified by this number in all public registers, including those of health services.

More than $95 \%$ of all births take place in hospitals, and they are registered by birth certificate in the Medical Birth Register. Information on births for the total number of women was obtained by register linkage of the Medical Birth Register and the women's personal identification numbers during the two-year follow-up period from 1 January 1984 to 31 December 1985 .

Information on spontaneous abortions in the source population was obtained by register linkage of the National Register of In-Patients and the personal identification numbers during the two years of follow-up from 31 July 1983 to 31 July 1985 . The results on spontaneous abortion and VDT work have been reported elsewhere (7).

In the source population, 24352 pregnancy outcomes were recorded in the two-year follow-up period, 661 of which were diagnosed with congenital malformation. A base sample of 2252 pregnancies $(9.2 \%)$ was drawn randomly from all the recorded pregnancies. Twins, triplets, and induced abortions were excluded.

\section{Recording of congenital malformations}

Data on congenital malformations derived from two sources, namely, the Medical Birth Register and the National Register of In-Patients. In the Medical Birth Register, all diagnoses on congenital malformations at birth are entered by the midwife in accordance with a standard recording form. Information on congenital malformations, birthweight, and gestational age was recorded from this register.

Table 1. Variables (potential confounders and effect modifiers) used in the multiple logistic regression analysis.

\begin{tabular}{ll}
\hline Covariable & Classification \\
\hline Maternal age & $<25$ years, 25-34 years, $\geq 35$ years \\
Previous pregnancies & Yes/no \\
Previous deliveries & Yes/no \\
Previous spontaneous & Yes/no \\
abortions & Three-level job-stress index based on \\
Job-stress factors & 12 questions on job stressors \\
& $\begin{array}{l}\text { Heavy lifting (yes/no) } \\
\text { Sitting more than } 1 \mathrm{~h} \text { at a time } \\
\text { during a workday (yes/no) }\end{array}$ \\
& Standing more than $1 \mathrm{~h}$ at a time \\
during a workday (yes/no)
\end{tabular}

If birth takes place at a hospital, the newborn is examined immediately by a physician, who diagnoses congenital malformations in accordance with the codes in the eighth revision of the International Classification of Diseases (ICD-8) of the World Health Organization.

For access to further information on congenital malformations, the personal identification numbers of the newborn were linked with the National Register of Inpatients; thus diagnoses of congenital malformations for children who had been hospitalized after birth or later in the follow-up period were provided. Diagnoses were recorded by the ICD- 8 codes. Since minor malformations are expected to be recorded with some degree of uncertainty, they were excluded from the study (not included by ICD-8 codes: $744.29,744.40-$ $744.49,744.80-744.99,745.19,745.49,745.59,745.89$, $745.99,752.10-752.13,752.19,752.29,752.49,755.00-$ $02,755.09-755.19,755.69,756.30-756.31,757.10-$ $757.99,758.99,759.00-09$.). For each child in this study, up to three diagnoses of congenital malformation from each register were recorded.

In our analysis the total number of children with congenital malformations constituted the case group. Cases were then grouped according to the main congenital malformation code of the ICD-8, and each group was considered a subcase group. A child was registered in more than one main ICD- 8 group if it had more than one malformation and therefore could belong to different main groups. The number of malformations in each group are presented later in the text.

\section{Assessment of exposure}

A questionnaire was sent to the case group and the base sample in September 1987. A request was made for information on occupational status, job title, job-stress factors, ergonomic factors, exposure to organic solvents, VDT work, life-style factors (such as tobacco and alcohol consumption), and health factors during pregnancy.

Exposure data from the base sample and the case group of congenital malformations were obtained for 1699 and 505 pregnancies, respectively, for response rates of 75 and $76 \%$, respectively.

\section{Analysis}

As the frequency of congenital malformations is a measure of prevalence at birth, prevalence odds ratios were estimated. The statistical analysis was based on unconditional logistic regression analysis (8) to eliminate confounding. The potential confounders considered in the analysis are shown in table 1 . A potential confounder was kept in the logistic regression model if the association with the dependent variable was statistically significant at the $5 \%$ level. In addition, two-factor interactions between VDT use and the potential confounders were examined, and those which contributed 
with information to the model were kept in the analysis. To increase the prevalence of VDT exposure, the study group was restricted to include only women who were employed during pregnancy. The final base sample consisted of 1365 pregnancies, and the case group of 421 children with congenital malformation.

The possible selection bias due to nonresponse was analyzed in a random sample $(14.5 \%)$ of nonresponders. These women were contacted by telephone and interviewed by interviewers who did not know the outcome of the pregnancy.

The possibility of selective memory is regarded as a serious problem in case-base studies. To elucidate this problem, we asked the VDT users for permission to contact their employers at the time of pregnancy. Three hundred and seven of the 555 women gave their consent, and a random sample of 200 women was drawn. By means of register linkage with the Labour Market Supplementary Pension Fund, the employers were identified, and a questionnaire on VDT use was forwarded to them. The response rate from the employers was $92.3 \%$.

\section{Results}

Of the employed women, $33.5 \%$ used a VDT during pregnancy. In the subgroup of clerical and administrative employees, the proportion was as high as $55.2 \%$. The prevalence rate of congenital malformations in children born to women in the base sample who were employed during pregnancy was $3.1 \%$. The corresponding rate for unemployed women in the study base was $2.5 \%$.

The estimated OR of congenital malformations by VDT users compared with non-VDT users during pregnancy was 0.96 [ $95 \%$ confidence interval $(95 \% \mathrm{CI})$ $0.76-1.20]$. The $\mathrm{OR}$ values for $\leq 10,11-20,21-30$, and $\geq 31 \mathrm{~h}$ of VDT use per week during pregnancy compared with no VDT use were $0.81,1.36,0.91$, and
0.91 , respectively, none of which was statistically different from unity (table 2).

A similar analysis carried out for clerical and administrative employees only did not alter these results. In conclusion, no association was found between the proportion of time spent working with a VDT regardless of the number of workhours per week (table 2).

The analysis did indicate an interaction between VDT use and the level of job stress. The OR for congenital malformations by VDT work and a low level of job stress was 0.86 (95\% CI $0.58-1.26$ ). The corresponding figures for women with medium or high levels of job stress were 0.94 (95\% CI $0.68-1.28)$ and 1.80 (95\% CI $0.77-4.24)$, respectively.

The association between VDT use and specific malformations can be seen from table 3. Many malformations were rare, and therefore no conclusions can be drawn concerning specific diagnoses. Unexpectedly, the relative prevalence ratio for hydrocephalus in relation to any VDT work was found to be $12.0(95 \%$ CI 1.38-104). VDT users had OR values slightly above 1 for having a child with defects of the ears, neck or face, blood vessels, lower digestive tract, urinary system, or with musculoskeletal or miscellaneous defects (table 3). For all other malformations, the observed $O R$ values were less than unity.

\section{Discussion}

About $80 \%$ of all employees in Denmark are members of a trade union. Since trade union registers are used to determine benefit eligibility, the registers are highly accurate.

The case-base design used in our investigation is a modification of the traditional case-referent design in that the cases were kept in the base sample (reference group). When one uses the same analysis in a case-base design as in a case-referent design, a bias in the estimated risk ratios may occur because of the double in-

Table 2. Odds ratios for congenital malformations according to work with a video display terminal among the employed women. (OR $=$ odds ratio, $95 \% \mathrm{Cl}=95 \%$ confidence interval of the adjusted odds ratio)

\begin{tabular}{|c|c|c|c|c|c|}
\hline \multirow{2}{*}{ VDT work ${ }^{a}$} & \multicolumn{2}{|c|}{$\begin{array}{c}\text { Number of } \\
\text { pregnancies }\end{array}$} & \multirow{2}{*}{$\begin{array}{c}\text { Crude } \\
\text { OR }\end{array}$} & \multirow{2}{*}{$\begin{array}{l}\text { Adjusted } \\
\mathrm{OR}^{\mathrm{b}}\end{array}$} & \multirow{2}{*}{$95 \% \mathrm{Cl}$} \\
\hline & $\begin{array}{l}\text { Case } \\
\text { group }\end{array}$ & $\begin{array}{l}\text { Base } \\
\text { sample }\end{array}$ & & & \\
\hline None & 284 & 909 & 1.00 & 1.00 & . \\
\hline Any & 137 & 456 & 0.96 & 0.95 & $0.76-1.20$ \\
\hline $\begin{array}{l}0-10 \mathrm{~h} / \text { week } \\
11-20 \mathrm{~h} / \text { week } \\
21-30 \mathrm{~h} / \text { week } \\
\geq 31 \mathrm{~h} / \text { week }\end{array}$ & $\begin{array}{l}64 \\
40 \\
19 \\
10\end{array}$ & $\begin{array}{r}256 \\
93 \\
61 \\
32\end{array}$ & $\begin{array}{l}0.80 \\
1.38 \\
1.00 \\
1.00\end{array}$ & $\begin{array}{l}0.81 \\
1.36 \\
0.91 \\
0.91\end{array}$ & $\begin{array}{l}0.59-1.11 \\
0.91-2.03 \\
0.53-1.57 \\
0.43-1.92\end{array}$ \\
\hline $\begin{array}{l}0-40 \% \text { VDT work } \\
41-70 \% \text { VDT work } \\
\geq 71 \% \text { VDT work }\end{array}$ & $\begin{array}{l}92 \\
26 \\
15\end{array}$ & $\begin{array}{r}320 \\
79 \\
43\end{array}$ & $\begin{array}{l}0.92 \\
1.05 \\
1.12\end{array}$ & $\begin{array}{l}0.93 \\
0.97 \\
1.04\end{array}$ & $\begin{array}{l}0.71-1.22 \\
0.60-1.56 \\
0.56-1.94\end{array}$ \\
\hline
\end{tabular}

\footnotetext{
a Detailed information on hours of VDT work/week was missing for four pregnancies in the case group and for 14 pregnancies in the base sample.

b Adjusted for potential confounders (see table 1).
} 
Table 3. Odds ratios for congenital malformations (main groups of the International Classification of Diseases) according to work with a video display terminal (VDT) among the women employed during pregnancy. (OR=odds ratio, $95 \% \mathrm{Cl}=95 \%$ confidence interval)

\begin{tabular}{|c|c|c|c|c|}
\hline & \multicolumn{2}{|c|}{$\begin{array}{c}\text { VDT work } \\
\text { (number of pregnancies) }\end{array}$} & \multirow[t]{2}{*}{ OR } & \multirow[t]{2}{*}{$95 \% \mathrm{Cl}$} \\
\hline & Yes & No & & \\
\hline Base sample & 456 & 909 & 1.00 & . \\
\hline \multicolumn{5}{|l|}{ Congenital malformation ${ }^{a}$} \\
\hline $\begin{array}{l}\text { Anencephaly (740) } \\
\text { Spina bifida (741) } \\
\text { Hydrocephalus (742) } \\
\text { Central nervous system, others (743) } \\
\text { Eyes (744) } \\
\text { Ears, neck and face (745) } \\
\text { Heart (746) } \\
\text { Blood vessels (747) } \\
\text { Respiratory system (748) } \\
\text { Cleft lip and/or palate (749) } \\
\text { Upper digestive tract (750) } \\
\text { Lower digestive tract (751) } \\
\text { Genitals (752) } \\
\text { Urinary system (753) } \\
\text { Club foot (754) } \\
\text { Extremities (755) } \\
\text { Musculoskeletal system (756) } \\
\text { Skin (757) }\end{array}$ & $\begin{array}{r}1 \\
3 \\
6 \\
1 \\
1 \\
3 \\
16 \\
8 \\
6 \\
10 \\
16 \\
12 \\
15 \\
8 \\
32 \\
5 \\
8 \\
.\end{array}$ & $\begin{array}{r}2 \\
6 \\
1 \\
4 \\
2 \\
3 \\
40 \\
17 \\
12 \\
22 \\
39 \\
20 \\
23 \\
13 \\
66 \\
22 \\
12 \\
\cdots\end{array}$ & $\begin{array}{c}1.00 \\
1.00 \\
12.0 \\
0.50 \\
1.00 \\
1.99 \\
0.94 \\
1.63 \\
0.98 \\
0.90 \\
0.66 \\
1.17 \\
1.06 \\
1.29 \\
0.83 \\
0.52 \\
1.78 \\
\cdots\end{array}$ & $\begin{array}{l}0.05-10.43 \\
0.21-3.80 \\
1.38-104 \\
0.03-3.38 \\
0.09-11.58 \\
0.38-10.25 \\
0.50-1.74^{\mathrm{b}} \\
0.62-4.30^{\mathrm{b}} \\
0.36-2.71^{\mathrm{b}} \\
0.41-1.94^{\mathrm{b}} \\
0.35-1.25^{\mathrm{b}} \\
0.55-2.45^{\mathrm{b}} \\
0.52-2.17^{\mathrm{b}} \\
0.48-3.43^{\mathrm{b}} \\
0.52-1.31^{\mathrm{b}} \\
0.18-1.49^{\mathrm{b}} \\
0.62-5.10^{\mathrm{b}}\end{array}$ \\
\hline $\begin{array}{l}\text { Skin (757) } \\
\text { Miscellaneous (758) } \\
\text { Chromosome defects (759) }\end{array}$ & $\begin{array}{r}3 \\
3 \\
5\end{array}$ & $\begin{array}{r}2 \\
16\end{array}$ & $\begin{array}{l}2.99 \\
0.70\end{array}$ & $\begin{array}{l}0.48-18.63 \\
0.24-1.99^{b}\end{array}$ \\
\hline
\end{tabular}

a Code of the International Classification of Diseases, eighth revision, in parentheses.

b Adjusted OR.

clusion. Greenland (9) has presented unbiased adjustment methods for calculating the risk ratio and confidence intervals in case-base designs. This method did not, however, alter the results. In the analysis all pregnancies were treated as independent events, and repeated pregnancies among the women were not taken into consideration in the analysis. However, most of the women only contributed with one pregnancy, and the effect of repeated pregnancies has been shown elsewhere to be a minor problem concerning statistical analysis (10). Not all women selected for the study responded to the questionnaire, and this lack of response might result in selection bias. In order to adjust for any selection bias due to nonresponse, we applied the findings from the subgroup of nonresponders, who had been interviewed by telephone, to the total group of nonresponders. The selection OR was 0.95 (11); this value indicated that selection bias due to nonresponse produced a small underestimation of the risk of congenital malformation among the VDT users.

Differential misclassification based upon self-reported exposure assessment after the delivery is another problem. In order to control for this problem, we also recorded exposure assessment by employers for a subset of participating VDT users. The sensitivity and specificity of being classified into one of the four VDT exposure groups were calculated according to the employers' answers as a corrective (11), and a rearrangement of exposure classification was performed. Calculation of the OR values after the rearrangement showed a bias away from the null hypothesis for the group exposed to a VDT for $11-20 \mathrm{~h} /$ week and a bias towards the null hypothesis for the group exposed to a VDT for $21-30$ and $\geq 31 \mathrm{~h} /$ week, in comparison with the group exposed to a VDT for $\leq 10 \mathrm{~h} /$ week. This finding may explain the excess risk of congenital malformations among the children of women exposed to a VDT for $11-20 \mathrm{~h} /$ week. The follow-up period for congenital malformations in the National Register of In-patients was from zero to two years. Our data could have been biased if VDT use increased during the follow-up period. This was not the case, however.

In this study we did not use self-reported data on pregnancy outcomes, but only data recorded in the computerized medical registers. The register data on congenital malformations have not been validated, and some misclassification of the outcome parameter may exist, even after removal of minor malformations. However, this type of misclassification is without doubt nondifferential and would lead to bias towards the null hypothesis.

Previous studies on congenital malformations and VDT work have not reported an increased risk for hydrocephalus, possibly because none of the studies were large enough to do so. Our finding of a statistically significant increased prevalence of hydrocephalus has to be interpreted with caution. It is a posterior finding based on small numbers. Kurppa et al (2) and Ericson \& Källén (3) found an increased OR for cardiac defects, although statistically nonsignificant. This finding was not confirmed in our study. The follow-up period may, however, have been too short to identify congenital cardiac defects, which are sometimes identified only later in life. 
Job stress has been suggested as a risk factor for congenital malformations and thus as a potential confounder in the earlier studies. Our finding of an association between job stress and VDT work, and between job stress and congenital malformations, may support this suggestion.

In conclusion, the present study does not support the hypothesis that VDT work in itself is a cause of congenital malformations.

\section{Acknowledgments}

We thank Professor J Olsen, Mr KO Larsen, and Ms L Helsborg for their scientific assistance; Ms B Waldstroem, Ms AC Dam, Ms LT Nielsen, and Ms AT Johansen for their technical and administrative assistance; and Ms $\mathrm{H}$ Brandt, Ms H Bräuner, Ms K Johansen, and Ms $\mathrm{H}$ Nicolaisen for performing the telephone interviews.

The study was financed by The Occupational Medical Research Fund in Aarhus, The Medical Research Fund, and The Health Fund.

\section{References}

1. Bergqvist UOV. Video display terminals and health: a technical and medical appraisal of the state of the art. Scand J Work Environ Health 1984;10(suppl 2):87p.

2. Kurppa K, Holmberg PC, Rantala K, Nurminen T,
Saxén L. Birth defects and exposure to video display terminals during pregnancy: a Finnish case-referent study. Scand J Work Environ Health 1985;11:353-6.

3. Ericson A, Källén B. An epidemiological study of work with video screens and pregnancy outcome: II. a casecontrol study. Am J Ind Med 1986;9:459-75.

4. McDonald AD, Cherry NM, Delorme C, McDonald JD. Visual display units and pregnancy: evidence from the Montreal survey. J Occup Med 1986;12:1226-31.

5. Goldhaber MK, Polen MR, Hiatt RA. The risk of miscarriage and birth defects among women who use visual display terminals during pregnancy. Am J Ind Med 1988; 13:695-706.

6. Miettinen OS. Theoretical epidemiology: principles of occurrence research in medicine. New York, NY: John Wiley \& Sons, 1985.

7. Nielsen CV, Brandt LPA. Spontaneous abortions in women using video display terminals. Scand J Work Environ Health 1990;16:323-8.

8. Breslow NE, Day NE. Statistical methods in cancer research: the analysis of case-control studies. Lyon: International Agency for Research on Cancer, 1980. (IARC scientific publications; no 32, vol 1.)

9. Greenland S. Adjustment of risk ratio in case-base studies (hybrid epidemiologic designs). Stat Med 1986; 5:579-84.

10. Butler WJ, Kalasinski LA. Statistical analysis of epidemiologic data of pregnancy outcomes. Environ Health Perspect 1989;79:223-7.

11. Kleinbaum DG, Kupper LL, Morgenstern H. Epidemiologic research: principles and quantitative methods. New York, NY: Lifetime Learning Publications, 1982.

Received for publication: 5 May 1989 